\title{
Mile Per Hour
}

National Cancer Institute

\section{Source}

National Cancer Institute. Mile Per Hour. NCI Thesaurus. Code C105500.

A unit of both speed (scalar) and velocity (vector), defined as the distance of one mile traveled per unit time equal to one hour. 